\title{
Directions for the implementation of information technologies in transport
}

\author{
Ivan Novikov ${ }^{1 *}$, Alexey Konev ${ }^{1}$, Nikolay Zagorodny ${ }^{1}$, and Alla Semykina ${ }^{1}$ \\ ${ }^{1}$ Belgorod State Technological University named after V.G. Shukhova, Belgorod, Russia
}

\begin{abstract}
The article presents an analytical review of information technologies in transport, identifies key areas, perspective development prospects.
\end{abstract}

\section{Introduction}

Like many sectors of the economy and manufacturing, the transport industry is at the stage of a digital transition. The governments of many countries have reached an understanding that the introduction of information technology into the daily and business life of people will make it possible to make a qualitative leap in development. The Government of the Russian Federation approved the Concept of training personnel for the transport complex until 2035 (Order of the Government of the Russian Federation of February 6, 2021, No. 255-r). According to this concept, the key challenges facing modern education in the field of transport are determined by the technological transformation of the transport industry and the world economy as a whole, digitalization, critical changes in the scientific and technological sphere, the structure of the labor market, based on IT solutions, cardinal shifts in approaches to organization. educational process and new educational technologies.

In this regard, it is necessary to highlight the main directions of development and implementation of information technologies in transport.

\section{Material and methods}

It is proposed to analyze the existing directions of development of information technologies in transport based on publications of leading domestic and foreign authors, materials of car manufacturers and leading enterprises of the industry.

\section{Theory}

Among the main directions of the use of information technologies in transport [1,2], the following can be distinguished:

- digital technologies in logistics [3-8];

- autonomous vehicles [9-12];

- transport information systems [13-15].

\footnotetext{
* Corresponding author: ooows@mail.ru
} 
In logistics, the use of Bigdata is widely used [8]. In logistics, the transportation of goods is influenced by many different factors: the loading of warehouses, traffic congestion, the condition of the vehicle fleet, the location of gas stations, service stations, etc. Optimization of the final stage of delivery of goods to the consumer is the most important task of logistics, for the solution of which all kinds of tools are required, including those based on working with big data. The cost of this task can be up to $28 \%$ of the total shipping cost.

For example, "Magnit" uses machine learning to predict demand in its stores: neural networks process big data on sales, consumer preferences, weather, holidays, social events and other external factors. Such BigData analytics allows you to identify non-linear relationships, predicting an increase in demand for goods. As a result of using this predictive analytics system, the retailer's revenue grew by 4 billion rubles a year.

A retailer such as "X5 RetailGroup" has launched an online big data analytics platform for its suppliers, which will allow the company's partners to generate reports on the history of purchases of their goods in the retail chains of the retailer. In this way, suppliers can analyze sales, identify sources of change in demand, learn about consumer switching to competing brands, determine customer rotation and changing needs.

Transport company"PEC" has launched its own Transportation Control Center (TCC) based on BigData. This significantly increased the accuracy of forecasting and planning of cargo transportation, as well as improved monitoring of balances in warehouses. The TCC allows real-time forecasting of the loading of 189 warehouses throughout Russia for a month in advance, processing more than 500 operations every second.

The main BigData technologies that are actively used in practice include:

- AkkaFramework for the development of parallel and distributed microservices on the JVM;

- SparkStreaming for streaming processing of big data;

- ApacheKafka for messaging between services;

- ApacheHadoop for storing historical data;

- PostgreSQL for urgent reporting;

- In-memoryDatabase for storing online data in memory.

The second direction of using information technologies in transport is the development of autonomous vehicles. According to the SAE classification, there are 5 levels of autonomy.

The first level of autonomy includes cars with adaptive cruise control: the car adheres to the speed of the vehicle in front. Lane Keeping Assist and Collision Warning Systems are also classified as Level 1.

Autonomous systems of the second level monitor the speed and control under certain conditions. They are able to correlate the speed of the vehicle with the speed of traffic, and also change the trajectory of movement when turning and rounding roads. Drivers constantly monitor the traffic situation in order to "take control" in an emergency.

The third level is conditional autonomy, when the autopilot system is on, the car can independently control the environment. This level assumes that the autopilot operates only at low speeds or in stable road conditions, such as on motorways. At the same time, the driver's hands must remain on the steering wheel, and if the situation becomes close to a traffic accident, then the car informs the driver about this, and he must take control.

The fourth level of autonomy includes all autonomous vehicles that move independently, but under the supervision of a driver in the car. No production vehicle currently equipped with autonomous features supports Level 4.

The fifth level of autonomy implies that the car independently moves on public roads without the accompaniment of a test driver or engineer. In theory, autonomous vehicles 
from Yandex, Waymo (a Google project), Renault and some other companies are capable of this, but so far there is no absolute confidence in their safety and reliability.

To ensure the autonomy of vehicles, such components are used as:

- front camera on the windshield (high resolution cameras);

- stereo cameras;

- optical system;

- radar;

- ultrasonic sensors;

- microphones;

- LiDAR.

However, at present, the laws of many countries prohibit the use of autonomous vehicles on public roads due to the lack of the necessary infrastructure. The organization of transport information systems will help to solve this problem.

There are three approaches to the organization of transport information systems, namely:

- infrastructure (cloud);

- autonomous;

- combined.

All approaches have both advantages and disadvantages (Table 1).

As a result of the analysis of publications, it was found that autonomous vehicles can significantly reduce the number of road accidents due to the fact that they exclude the influence of the human factor on the occurrence of a road accident.

Table 1.Comparative characteristics of approaches to the organization of information systems in transport.

\begin{tabular}{|c|c|c|}
\hline Approachname & Dignity & Disadvantages \\
\hline Infrastructure & $\begin{array}{c}\text { high reliability; } \\
\text { flexibility of the system; } \\
\text { scalability; } \\
\text { low requirements for unmanned } \\
\text { vehicles (UAVs); } \\
\text { low cost of UAVs } \\
\end{array}$ & $\begin{array}{l}\text { high cost of the entire } \\
\text { complex as a whole; } \\
\text { high system latency; } \\
\text { dependence on infrastructure }\end{array}$ \\
\hline Autonomous & $\begin{array}{c}\text { low cost of the entire complex as a } \\
\text { whole; } \\
\text { independence from infrastructure; } \\
\text { low system latency; } \\
\text { versatility }\end{array}$ & $\begin{array}{l}\text { high requirements for UAVs; } \\
\text { high cost of UAVs; } \\
\text { incompatibility with } \\
\text { infrastructure }\end{array}$ \\
\hline Combined & $\begin{array}{c}\text { flexibility of the system; } \\
\text { scalability; } \\
\text { versatility; } \\
\text { low system latency; } \\
\text { independence from infrastructure }\end{array}$ & $\begin{array}{l}\text { high cost of the entire } \\
\text { complex as a whole; } \\
\text { high cost of UAVs; } \\
\text { high requirements for UAVs }\end{array}$ \\
\hline
\end{tabular}

The procedure for digital transformation in logistics should include a number of design solutions related to the formation of a communication network structure, an integrated supply chain planning system, an ecosystem of digital twins, as well as a digital platform for controlling and monitoring events in the supply chain.

It was revealed that without a deep study of the issue of transport information systems, it is impossible to connect digital technologies in logistics and autonomous vehicles. 


\section{Results and discussion}

In an era of digital transformation and technology penetration, companies can make smarter and more informed decisions. Analysis and accounting of big data is also necessary in logistics, as it allows you to have better manageability of supply chains, to plan wisely and have a real, factual picture of the current state of affairs at every moment in time.

In the field of autonomous vehicle design, there is currently a lot of attention to components, but at the same time, decision algorithms are an integral part. It is this direction that should be given close attention.

For the most efficient organization of logistics operations and the operation of autonomous vehicles, it is necessary to implement transport information systems. This approach will reduce the costs of production processes, improve road safety and reduce the negative impact of transport on the environmental situation in large cities.

\section{References}

1. S.Gringard,Internet of Things. The future is already here, $\mathrm{M} .:$ Albina publisher,188 $\mathrm{p}$. (2017)

2. E.P.Zaramenskikh, I.E. Artemiev,Internet of Things. Research and Application Area, Moscow: INFRA-M, 188 p., (2017)

3. A.V.Bogdanova, I.V.Terenina,Application of augmented reality technology in logistics,Logistics - Eurasian bridge, pp. 313-318, (2016)

4. Yu.G.Borisov, A.M.Kumratova,Problems of development of the cloud technologies market in Russia,Information society: current state and development prospects,pp. 350-352, (2017)

5. A.N.Novikov, T.A.Dudnik, V.VVasilyeva., M.V.Kulev,Digital technologies in logistics as a tool for sustainable development, III Arrigiev readings on the topic: "Russia's path to the future world order", Materials of the international scientific and practical conference in 2 parts, Oryol, pp. 97-108, (2020)

6. V.I.Sergeeva, Digital technologies in logistics and supply chain management: an analytical review, Nat. issled. University Higher School of Economics, Ed. House of the Higher School of Economics, 192 p., (2020)

7. S.Tiwari, H.M.Wee, Y.Daryanto,Big data analytics in supply chain managementbetween 2010 and 2016: Insights to industries, Computers \& IndustrialEngineering, v.115.pp. 319-330, (2018)

8. S.F.Wamba, S.Akter,Big data analytics for supply chain management: A literature review and research agenda,Presented at the Workshop on Enterprise andOrganizational Modeling and Simulation.Springer, pp. 61-72 (2015)

9. W. Gruel, J. M. Stanford, Assessing the Long-Term Effects of Autonomous Vehicles:a speculative approach, Transportation Research Procedia 13, pp. 18 - 29, ( 2016 )

10. S.Agriestib,F.Brevia, P.Gandinia, G.Marchionnia, R.Parmarc, M.Pontia, L.Studera,Impact of Driverless Vehicles on Urban Environment and Future Mobility, Transportation Research Procedia 49,pp. 44-59, (2020)

11. M.Martínez-Díaz, F.Soriguera,Autonomous vehicles: theoretical and practical challenges, Transportation Research Procedia 33, pp. 275-282, (2018)

12. Đ.Petrović, R.Mijailović, D.Pešić,Traffic Accidents with Autonomous Vehicles: Type of Collisions, Manoeuvres and Errors of Conventional Vehicles' Drivers, Transportation Research Procedia 45, pp. 161-168, (2020) 
13. A.N.Novikov, I.P.Emelyanov, A.O.Tarasov, The use of intelligent systems for the organization of non-stop movement of heavy vehicles on city roads, Intelligent information systems: trends, problems, prospects. Collection of scientific articles of the 8th International Scientific and Practical Conference "IIS-2020". Southwest State University, Moscow Polytechnic University, Kursk, pp. 148-152, (2020)

14. T.Palonena,R.Viri. Benchmarking public transport level-of-service using open data, Transportation Research Procedia 42, pp. 100-108, (2020)

15. A.Novikov, S.Eremin,Patterns of passenger traffic formation in urban public transport, Transportation Research Procedia 14, pp. 483-490, (2020) 